\title{
Nifedipine improves blood flow and oxygen supply, but not steady-state oxygenation of tumours in perfusion pressure- controlled isolated limb perfusion
}

\author{
O Thews*,', M Hummel', DK Kelleher', B Lecher' and P Vaupel' \\ 'Institute of Physiology and Pathophysiology, University of Mainz, Duesbergweg 6, 55099 Mainz, Germany
}

Isolated limb perfusion allows the direct application of therapeutic agents to a tumour-bearing extremity. The present study investigated whether the dihydropyridine-type $\mathrm{Ca}^{2+}$-channel blocker nifedipine could improve blood flow and oxygenation status of experimental tumours during isolated limb perfusion. Perfusion was performed by cannulation of the femoral artery and vein in rats bearing DS-sarcoma on the hind foot dorsum. Perfusion rate was adjusted to maintain a perfusion pressure of $100-140 \mathrm{mmHg}$ throughout the experiment. Following equilibration, nifedipine was continuously infused for $30 \mathrm{~min}(8.3 \mu \mathrm{g}$ $\left.\min ^{-1} \mathrm{~kg}^{-1} \mathrm{BW}\right)$. During constant-pressure isolated limb perfusion, nifedipine can significantly increase perfusion rate $(+100 \%)$ and RBC flux (+60\%) through experimental leg tumours. 'Steal phenomena' in favour of the surrounding normal tissue and oedema formation were not observed. Despite the increased oxygen availability (+63\%) seen upon application of this calcium channel blocker, nifedipine does not result in a substantial reduction of tumour hypoxia, most probably due to an increase in $\mathrm{O}_{2}$ uptake with rising $\mathrm{O}_{2}$ supply to the tumour-bearing hind limb. Nifedipine application during isolated limb perfusion can enhance tumour microcirculation and may therefore promote the delivery (pharmacokinetics) of anti-cancer drugs to the tumour and by this improve the efficacy of pressure-controlled isolated limb perfusion.

British Journal of Cancer (2002) 87, 1462 - |469. doi:|0.1038/sj.bjc.66006। I www.bjcancer.com

(C) 2002 Cancer Research UK

Keywords: calcium channel blocker; isolated limb perfusion; nifedipine; tumour perfusion; tumour oxygenation; tumour vascular resistance

Isolated limb perfusion (ILP) is a treatment modality for malignancies of the extremities in which the tumour-bearing limb is isolated from the patient's circulatory system and perfused separately. This procedure allows the administration of anti-cancer agents to the tumour at high doses with only a minimum risk of systemic toxicity. High-dose regional chemotherapy was one of the first concepts in ILP which was complemented more recently by the application of cytokines and immune-modulators frequently in combination with hyperthermia (Omlor et al, 1995; Eggermont et al, 1996; Pisters et al, 1997; Schraffordt-Koops et al, 1998; Seynhaeve et al, 2002). Since its introduction into the clinical setting (Creech et al, 1958), ILP with high-dose chemotherapy alone or in combination with biological agents has been used for the treatment of loco-regionally advanced melanomas and locally advanced soft tissue sarcomas not amenable to surgical resection (for a review see Hohenberger and Kettelhack, 1998).

The response to chemo- or cytokine-therapy may however be compromised by 'biological' factors such as tumour blood flow and microcirculation, tissue oxygenation or $\mathrm{pH}$ distribution. The individual tumour microenvironment is a paramount determinant in the outcome of non-surgical treatments (Vaupel et al, 1989; Höckel and Vaupel, 2001). For example, bulky tumours, which are an indication for ILP in sarcoma treatment, often show a progressive deterioration and heterogeneity of tumour blood flow

*Correspondence: Dr O Thews; E-mail: OLTHEWS@uni-mainz.de Received 22 April 2002; revised 23 August 2002; accepted 30 August 2002 during growth which in turn is responsible for diffusion- and perfusion-limited hypoxia resulting in a reduced efficacy of oxygen-dependent agents (e.g., anthracyclines, cyclophosphamide or melphalan; Vaupel et al, 2001). At the same time a poor and inhomogeneous delivery of anti-cancer agents will diminish the cytotoxic effect. For this reason, supportive treatment modalities might be helpful which lead to an improvement or homogenisation of tumour blood flow and/or a reduction of hypoxia already present in many experimental or human tumours.

One group of drugs that might achieve these goals (and by this might increase the efficacy of ILP) are calcium channel blockers (CCB). In experimental tumour therapy, CCBs have been of broad interest because of their ability to modify tumour blood flow and improve oxygenation status.

Blood flow modification following administration of these agents results from a dilation of resistance vessels and a reduction in blood viscosity. Over the last two decades, CCBs (e.g., flunarizine) have been shown to improve tumour blood flow, oxygen availability (Kaelin et al, 1984; Vaupel and Menke, 1987, 1989), tumour oxygenation (Dewhirst et al, 1992) and to increase tumour radiosensitivity (Hill and Stirling, 1987; Wood and Hirst, 1988, 1989). However, the proposed increase in tumour blood flow resulting from a vasodilatation of vessels feeding the tumour is strongly dependent on the maintenance of a stable perfusion pressure which could not be achieved with all types of CCBs. This might however not be a problem in the case of the isolated perfusion of tumour-bearing limbs by an extracorporeal circuit as performed clinically, since perfusion pressure can be regulated by 
enhancing or lowering perfusate flow rate by means of an external pump. Thus, a CCB-induced drop in perfusion pressure could easily be compensated by an increase in the perfusion rate. Besides their impact on the tumour oxygenation via an increase in the $\mathrm{O}_{2}$ supply, CCBs also seem to be able to improve the $\mathrm{O}_{2}$ status directly by reducing oxygen consumption (Biaglow et al, 1986; Vaupel and Mueller-Klieser, 1986).

In addition, CCBs show a chemosensitising effect (Helson, 1984) which is thought to be independent of effects on the classical slow inward calcium channel. The ability of verapamil and other CCBs to reverse multi-drug resistance is linked to the interaction of the CCBs with the P-glycoprotein in the membrane of resistant tumour cells (Cornwell et al, 1987). The enhanced anti-tumour and anti-metastatic potential of cisplatin in combination with nifedipine in mice was attributed to the inhibition of tumour cellplatelet aggregation and inhibition of platelet-enhanced tumour cell adhesion to endothelial cells in vitro and in vivo by CCBs of the dihydropyridine type (Honn et al, 1985; Onoda et al, 1989).

The present study investigated the possibility of using nifedipine to improve perfusion and oxygenation status of experimental tumours during pressure-controlled ILP and thus to possibly enhance the efficacy of chemotherapy. Nifedipine was chosen rather than other CCBs since dihydropyridine derivatives preferentially block calcium channels in the plasma membrane of arterial smooth muscle cells rather than the myocardium and therefore function in contrast to other classes of CCBs predominantly as vasodilators (Jirtle, 1988; Robertson and Robertson, 1996), a property which may be particularly suitable for increasing perfusion rate in a pressure-controlled system.

\section{MATERIALS AND METHODS}

\section{Animals and tumours}

Male Sprague Dawley rats (Charles River Deutschland, Sulzfeld, Germany; body weight 200-320 g) housed in our animal care facility were used in this study. They received a standard diet and acidified water ad libitum. Experimental tumours were grown following subcutaneous injection of DS-ascites cells $(0.4 \mathrm{ml}$; approximately $10^{4}$ cells per $\mu \mathrm{l}$ ) into the dorsum of the hind foot.
Tumours were used when they reached a volume of between 0.8 and $1.3 \mathrm{ml}, 4$ to 9 days after tumour implantation corresponding to a tumour mass of $0.5 \%$ of the body weight (Workman et al, 1998). Tumours were implanted on both feet whereby one leg was used for isolated limb perfusion and the contralateral leg as an additional control for the metabolic and bioenergetic parameters. Studies had previously been approved by the regional ethics committee and were conducted according to UKCCCR guidelines (Workman et al, 1998) and to the German Law for Animal Protection.

\section{Nifedipine}

Under protection from direct light, $2 \mathrm{mg}$ nifedipine (Sigma, Deisenhofen, Germany) was dissolved in $10 \mathrm{ml} 96 \%$ ethanol. Further dilution was made with isotonic saline resulting in a concentration of $0.1 \mathrm{mg} \mathrm{ml}^{-1}$. This stock solution was added continuously at a rate of $0.5 \mathrm{ml} \mathrm{h}^{-1} \mathrm{~kg}^{-1}$ body weight (Harvard infusion/withdrawal pump, Harvard, Edenbridge, UK) to the perfusion medium via a catheter placed in the femoral artery resulting in a nifedipine dose of $8.3 \mu \mathrm{g}$ nifedipine $\min ^{-1} \mathrm{~kg}^{-1}$ body weight. An equivalent volume of the vehicle was infused into control animals.

\section{Isolated limb perfusion}

A single-pass ILP of the tumour-bearing extremity was performed (in contrast to the earlier attempts of Nagel et al (1987) where a closed blood circuit was used) using a perfusion system consisting of a peristaltic roller pump (mp13GJ-4, Ismatec, Zürich, Switzerland), a capillary oxygenator (SPS40002-P, Fresenius, Bad Homburg, Germany), a water-filled heat exchanger used to maintain a perfusate blood temperature of 36.5 to $37.5^{\circ} \mathrm{C}$, polyethylene cannulas and silicone tubing (Figure 1). The perfusion medium was heparinised blood (20 i.u. $\mathrm{ml}^{-1}$ whole blood) obtained from donor rats. Prior to use, blood was diluted to a haematocrit of $25 \%$ with bicarbonate-buffered oxypolygelatine (55 $\mathrm{g} \mathrm{l}^{-1}$, Gelifundol, Biotest Pharma, Dreieich, Germany), an isotonic colloidal blood plasma substitute solution which is used in the clinical setting. By using this drug for haemodilution an

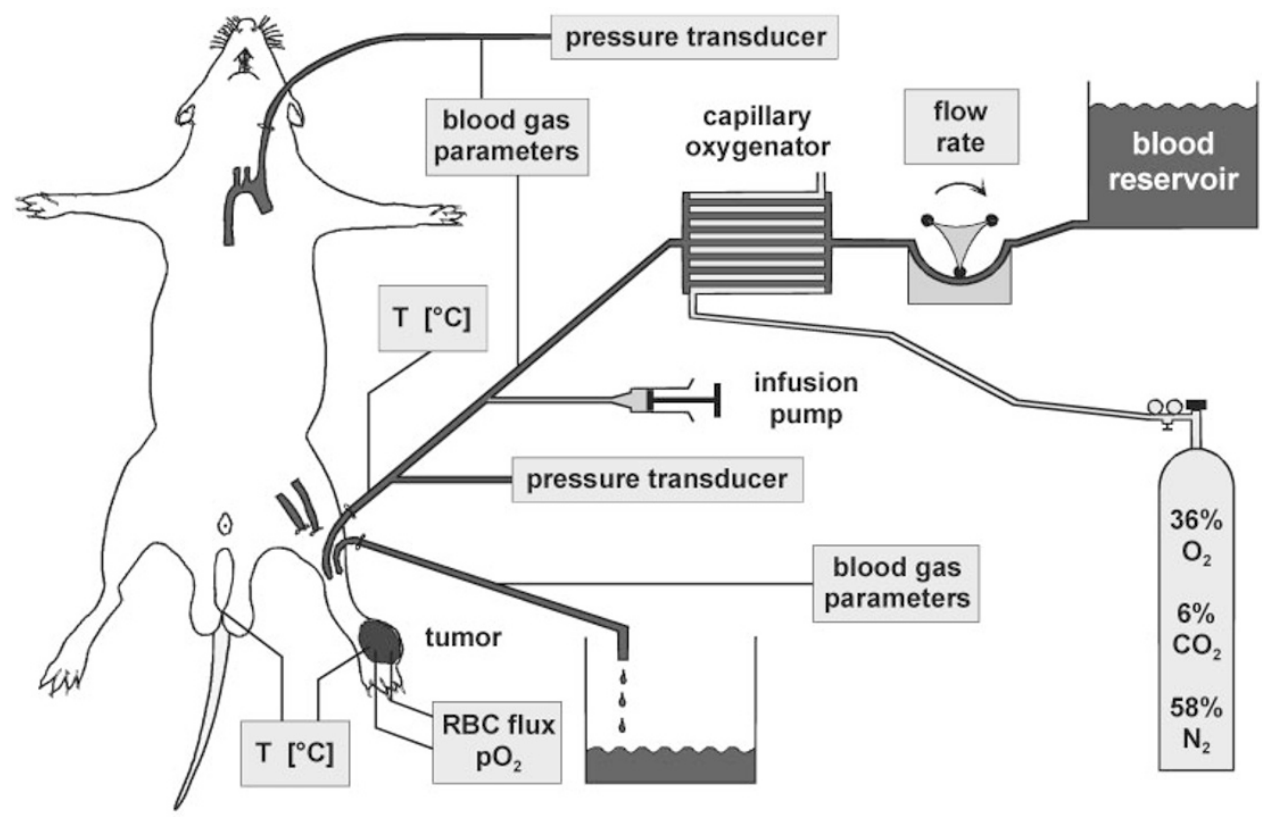

Figure I Experimental set-up for isolated limb perfusion in the rat. 
isotonic and isooncotic perfusate was obtained. Mean haemoglobin concentration $(\mathrm{cHb})$ was $77 \mathrm{~g}^{-1}$. Mean glucose and lactate levels were 6.1 and $6.9 \mathrm{mM}$, respectively. Blood was oxygenated with a humidified gas mixture containing $6 \% \mathrm{CO}_{2}, 36 \% \mathrm{O}_{2}$ and $58 \%$ $\mathrm{N}_{2}\left(\mathrm{v} \mathrm{v}^{-1}\right)$.

When tumours had reached the target volume, animals underwent general anaesthesia (sodium pentobarbital, $40 \mathrm{mg} \mathrm{kg}^{-1}$ i.p., Narcoren $^{\mathrm{TM}}$, Merial, Hallbergmoos, Germany) and polyethylene catheters were surgically placed into the thoracic aorta via the left common carotid artery and into the right external jugular vein. Mean arterial blood pressure (MABP) was continually monitored through the connection of the arterial catheter to a Statham pressure transducer (type P23 ID, Gould, Oxnard, CA, USA). Arterial blood gas analysis was performed before and during ILP experiments using a pH/blood gas analyser (type ABL 5, Radiometer, Copenhagen, Denmark). Since the anaesthetic agent used is known to induce respiratory depression in high concentrations, the depth of anaesthesia was assessed by monitoring arterial blood pressure and blood gas status to ensure that these parameters remained within the physiological range throughout the experimental period.

Heparin (100 i.u. $\mathrm{kg}^{-1}$, body weight) was injected intravenously to prevent coagulation. An incision was made in one groin and the femoral artery and vein were exposed. After ligation of accessible collaterals, the femoral vessels were cannulated (Vasofix braunule 20 G, B Braun Melsungen, Melsungen, Germany, and AbbocathT, 20 G, Abbott Ireland, Sligo, Ireland, respectively), flushed with $2 \mathrm{ml}$ of warmed oxypolygelatine and then connected to the perfusion equipment. Blood flow in deep-seated collaterals was restricted by a groin tourniquet which was tightened upon commencement of the perfusion. Perfusate flow rate was varied (range: $0.27-$ $2.63 \mathrm{ml} \mathrm{min}^{-1}$ ) to achieve a constant perfusion pressure (PP) of approximately 100 to $140 \mathrm{mmHg}$ in order to maintain an adequate tissue perfusion which might otherwise be impaired with PP approximately $15 \mathrm{mmHg}$ below the systemic MABP (Fontijne et al, 1985a,b). Perfusion pressure in the isolated leg was continuously monitored through the connection of the femoral artery to a Statham pressure transducer via a three-way stopcock.

The duration of isolated perfusion of approximately $60 \mathrm{~min}$ including $30 \mathrm{~min}$ of drug application was chosen in accordance with clinical studies and with results dealing with optimum conditions for ILP in the animal model (de Wilt et al, 1999). Throughout all experiments, animals lay supine on a heated operating pad and rectal temperature was maintained at $37.5-38.5^{\circ} \mathrm{C}$. Animals breathed room air spontaneously.

\section{Laser doppler flowmetry}

A multi-channel laser Doppler perfusion monitor (semiconductor laser diode, wavelength $780 \mathrm{~nm}$, output power $1-2.5 \mathrm{~mW}$, cutoff frequency $15 \mathrm{~Hz}$, Oxford Array, Oxford Optronix, Oxford, UK) was used to measure red blood cell flux (RBC flux). Details of this method have been described earlier by Kelleher et al (1995, 1998b). This method uses the Doppler shift (i.e. the frequency change that light undergoes when reflected by objects in motion, such as RBCs) and has been proposed to be a valid method for the monitoring of microcirculatory function in small, discrete tissue areas (for a review see Smits et al, 1986). The measured flux predominantly represents the RBC flux within the illuminated volume, regardless of flow direction, and is defined as the product of the local velocity and concentration of RBCs in the measured volume which encompasses a hemisphere with a radius of approximately $0.1 \mathrm{~mm}$. RBC flux signals were obtained from up to two peripheral and one central locations within the tumour using needle probes (Model array NP, o.d. $0.4 \mathrm{~mm}$ ). A small skin incision was made with a 24-gauge needle for insertion of the needle probe so that bleeding from the wound was minimised. Total backscattered light was also recorded during the monitoring period to optimise probe positioning, minimise tissue compression (which might impair circulatory function) and ensure a constant probe location. Flux artefacts, due to alteration of the probe position (e.g., as a result of movement), additionally result in sudden changes of the total backscattered light. In the few instances where this occurred, the flux values concerned were excluded from the final evaluation. At the end of the experiment, the laser Doppler probes were left in place, the animal given an overdose of anaesthetic, the cannula in the femoral artery disconnected from the perfusion equipment and the 'biological zero' laser Doppler signal was established and subtracted from flux values which were then expressed as relative RBC flux and represent percentage values related to the RBC flux value determined immediately prior to nifedipine application.

Although, attempts were made to maintain the PP at a constant level during ILP, slight pressure changes $( \pm 5-10 \mathrm{mmHg})$ occurred. In order to assess whether changes in RBC flux were due to variations in PP or the result of nifedipine-induced vasodilation, the relative tumour vascular resistance (TVR) was calculated as a measure of the resistance to flow. The TVR was defined by the ratio of the MABP (or PP) and the RBC flux. This parameter is suitable for assessment of changes in the vascular diameter from variations in tumour blood flow.

\section{Tumour oxygen tension}

Mean tumour oxygen partial pressure $\left(\mathrm{pO}_{2}\right)$ was assessed polarographically using a flexible $\mathrm{O}_{2}$-sensitive catheter electrode (length of the $\mathrm{O}_{2}$-sensitive cathode $5 \mathrm{~mm}$, outer catheter diameter $0.35 \mathrm{~mm}$, LICOX, GMS, Kiel-Mielkendorf, Germany) which was inserted into the centre of the tumour for continuous monitoring of tumour $\mathrm{pO}_{2}$. Before each experiment, the $\mathrm{pO}_{2}$ electrode was calibrated with room air in a chamber with constant temperature, taking the ambient barometric pressure into account.

After the surgical procedure, animals were allowed to stabilise and measurements commenced once constant baseline readings for PP, RBC flux and tumour oxygen tension were obtained for at least $20 \mathrm{~min}$ (if constant baseline readings could not be achieved values were excluded from further data analysis). Thereafter baseline values for blood flow rate, $\mathrm{PP}, \mathrm{RBC}$ flux and tumour $\mathrm{pO}_{2}$ were continuously recorded before the commencement of nifedipine or vehicle infusion and throughout the $30 \mathrm{~min}$ infusion period. Arterial and venous perfusate samples were taken at $\mathrm{t}=0$ (immediately prior to ILP), 15, and $30 \mathrm{~min}$ to assess $\mathrm{pH} / \mathrm{blood}$ gas status (type ABL 5, Radiometer, Copenhagen, Denmark) as well as glucose and lactate concentrations which were determined enzymatically using standard test kits (1442457 and 256773; Boehringer-Mannheim, Mannheim, Germany).

\section{Metabolite concentrations}

In an additional series of experiments, the tumour of the isolated perfused leg and of the contralateral hind limbs of the anaesthetised animals were surgically removed and rapidly frozen in liquid nitrogen immediately following termination of the perfusion procedure $(30 \mathrm{~min}$ of equilibration plus $30 \mathrm{~min}$ of nifedipine or vehicle infusion) and the tumours subsequently removed. The tumours were ground to a fine powder and subsequently freezedried. Thereafter, glucose and lactate concentrations were assayed enzymatically using standard test kits (1442457 and 256773; Boehringer-Mannheim, Mannheim, Germany). Concentrations of adenosine triphosphate (ATP), adenosine diphosphate (ADP) and adenosine monophosphate (AMP) were determined by highperformance liquid chromatography (HPLC, for details see Krüger et al, 1991). In brief, $2-3 \mathrm{mg}$ aliquots of freeze-dried tissue were extracted with $0.3 \mathrm{M}$ perchloric acid, centrifuged and the supernatant neutralised with $2 \mathrm{M}$ potassium hydroxide and diluted 
$1: 2$ with the mobile HPLC-phase. Concentrations were then determined using reversed-phase high-performance liquid chromatography (HPLC) and UV-detection at $254 \mathrm{~nm}$. The isocratic separation was performed by a Superspher RP 18 endcapped column $(250 \times 4 \mathrm{~mm}$; Knauer, Berlin Germany) and a guard cartridge system $(5 \times 4 \mathrm{~mm})$. The mobile phase consisted of $0.05 \mathrm{M}$ ammonium dihydrogen phospate, $0.01 \mathrm{M}$ tetrabutylammonium hydroxide and $11.5 \%$ acetonitrile $\left(\mathrm{v} \mathrm{v}^{-1}\right)$, adjusted to

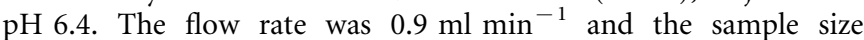
$40 \mu \mathrm{l}$. Concentrations of all metabolites are expressed as $\mu \mathrm{mol} \mathrm{g}^{-1}$ tissue wet weight. Wet weight was estimated from tissue samples as follows: tumours (perfused for $1 \mathrm{~h}$ ) were excised from the hind foot dorsum, skin was removed and wet weight recorded. Tumours were dried at $60^{\circ} \mathrm{C}$ until constant weight readings were attained. The tissue water content was the same in perfused and in untreated tumours $(82.1 \pm 0.2 \%$ vs $82.0 \pm 0.1 \%)$ of comparable volume. Oedema formation during ILP can thus be excluded.

\section{Statistical analysis}

Results are expressed as means \pm s.e.m. unless stated otherwise. Differences between groups were assessed by the two-tailed Wilcoxon test for paired or unpaired samples as appropriate. The significance level was set at $\alpha=5 \%$ for all comparisons.

\section{RESULTS}

Baseline PP in the isolated-perfused leg before administration of nifedipine or vehicle was $141 \pm 8$ and $131 \pm 7 \mathrm{mmHg}$, respectively, at comparable baseline perfusate flow rates of $1.09 \pm 0.10 \mathrm{ml}$ $\min ^{-1}$ in the nifedipine group and of $1.16 \pm 0.12 \mathrm{ml} \mathrm{min}^{-1}$ in control animals. Upon nifedipine application, PP initially dropped (with lowest values at $\mathrm{t}=3 \mathrm{~min}$ ) to $81 \%$ of the baseline value. Thereafter however, the decrease was intentionally compensated by the increased perfusate flow rate resulting in a constant PP of between 130 and $135 \mathrm{mmHg}$. During nifedipine application, the perfusate flow rate had to be increased by almost $100 \%$ in order to maintain a constant PP (Figure 2), suggesting a pronounced nifedipine-induced vasodilation either in the tumour or in the normal tissue of the perfused hind limb (e.g., skeletal muscle). After discontinuation of nifedipine infusion, the PP increased within $5 \mathrm{~min}$ so that the perfusate rate had to be reduced to achieve pressure-constant conditions (Figure 2). Application of the vehicle alone resulted in only a slight decrease in perfusion pressure by $2 \%$ of the baseline value so that the perfusate flow rate remained almost constant during vehicle administration (Figure 2).

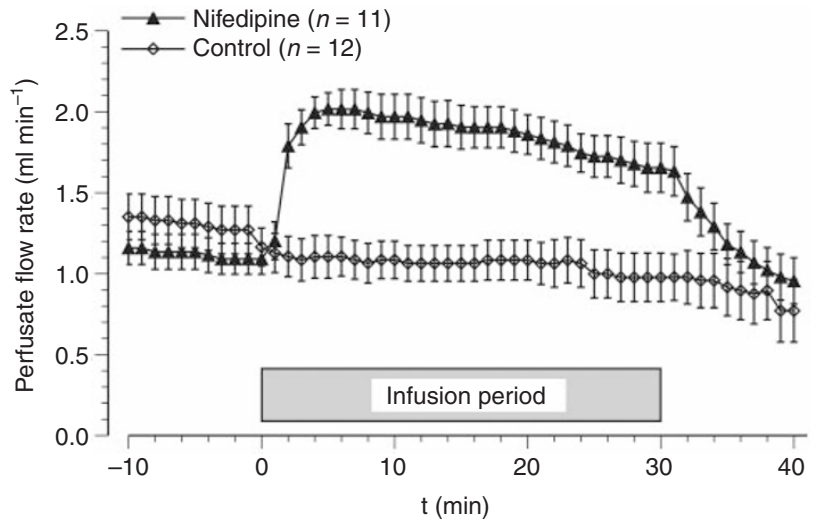

Figure 2 Perfusate flow rate during isolated limb perfusion upon application of nifedipine or vehicle alone (gray bar). Data represent mean \pm s.e.m. ( $n=$ number of perfusion experiments).
At constant PP during nifedipine application, the mean $R B C$ flux in the tumours increased by approximately $60 \%$ whereas the TVR was reduced by $40 \%$ indicating a vasodilation of vessels feeding the tumour (Figure 3). In control animals, the opposite was observed, with a moderate reduction in RBC flux and an increase in vascular resistance revealing a slight vasoconstriction upon vehicle application.

Since the oxygen content of the arterial perfusate was maintained by oxygenising the blood with a capillary oxygenator to give an oxyhaemoglobin saturation of almost $100 \%$, the increase in perfusate flow rate during nifedipine application resulted in a pronounced increase in $\mathrm{O}_{2}$ delivery to the perfused limb. However, the improved supply had only a minor impact on the $\mathrm{O}_{2}$ partial pressure of the tumour tissue. Figure 4 illustrates that during nifedipine infusion only a minor increase in the mean tumour $\mathrm{pO}_{2}$ of approximately $2 \mathrm{mmHg}$ occurred. The application of the vehicle alone resulted in a slight worsening in mean tumour $\mathrm{pO}_{2}$ (a decrease of up to $3 \mathrm{mmHg}$, Figure 4) but taking the pronounced inter-tumour variability of the oxygenation changes into account, these differences were not statistically significant. The improved $\mathrm{O}_{2}$ supply therefore did not result in an improvement of tumour oxygenation. Since the oxygenation status of a tissue results from a dynamic steady state between $\mathrm{O}_{2}$ supply and $\mathrm{O}_{2}$ uptake, one possible explanation of this result might be an increased $\mathrm{O}_{2}$ utilisation during nifedipine infusion. Although the $\mathrm{O}_{2}$ supply was nearly doubled by nifedipine application, the arterio-venous $\mathrm{O}_{2}$ concentra-

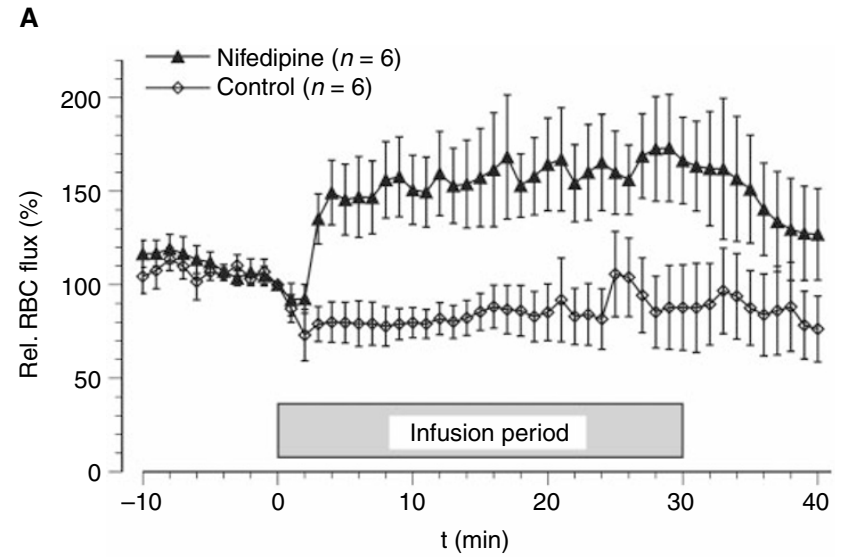

B

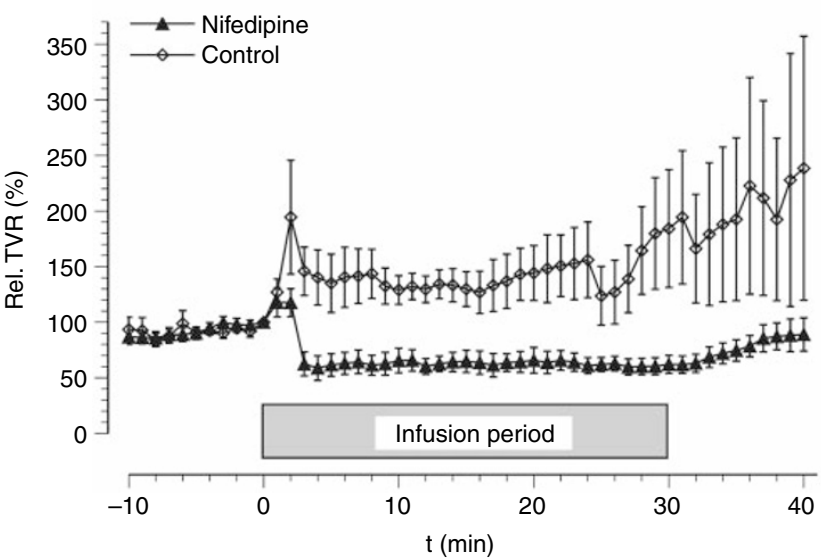

Figure 3 (A) RBC-flux and (B) resistance to flow (TVR) during isolated limb perfusion upon application of nifedipine. Data represent mean \pm s.e.m. (n=number of tumours investigated; the RBC flux value of each tumour was obtained by calculating the mean values from up to three individual probes located in central and peripheral regions of the tumour). 
tion difference $\left(\mathrm{avDO}_{2}\right)$ remained almost constant (Table 1), indicating a significant increase in $\mathrm{O}_{2}$ uptake following the improved $\mathrm{O}_{2}$ delivery caused by nifedipine administration. If all experiments (nifedipine treatment and controls) were taken together, a linear correlation $\left(\mathrm{r}^{2}=0.606\right)$ was seen between the $\mathrm{O}_{2}$ supply to the tumour-bearing leg and the $\mathrm{O}_{2}$ uptake into the tumour (Figure 5 ), a phenomenon which might explain the lack of a substantial tumour $\mathrm{pO}_{2}$ increase during nifedipine administration.

As a result of the reduced haematocrit $(25 \%)$ used in the perfusate, the oxygen supply during ILP per se seems to be somewhat

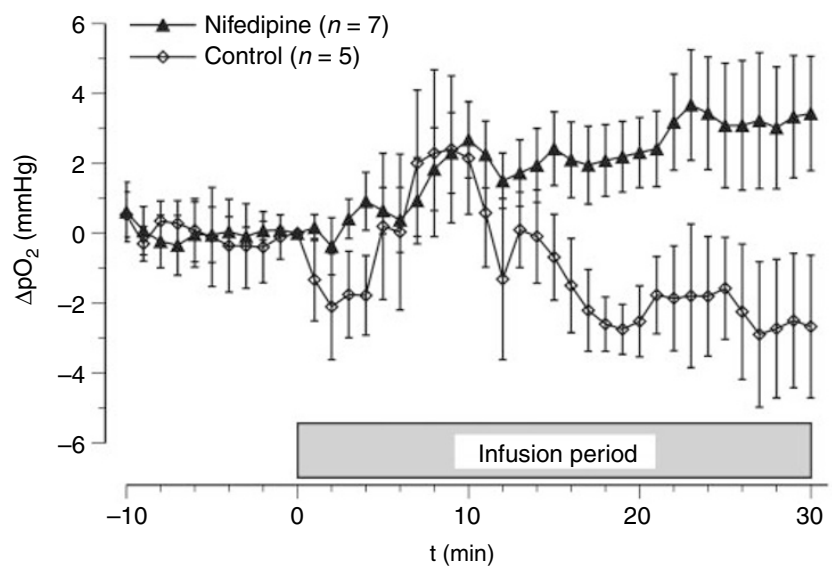

Figure 4 Changes of mean tumour $\mathrm{pO}_{2}$ during isolated limb perfusion upon application of nifedipine compared to the $\mathrm{pO}_{2}$ value immediately prior to the commencement of drug infusion. Data represent mean \pm s.e.m. ( $n=$ number of tumours investigated)

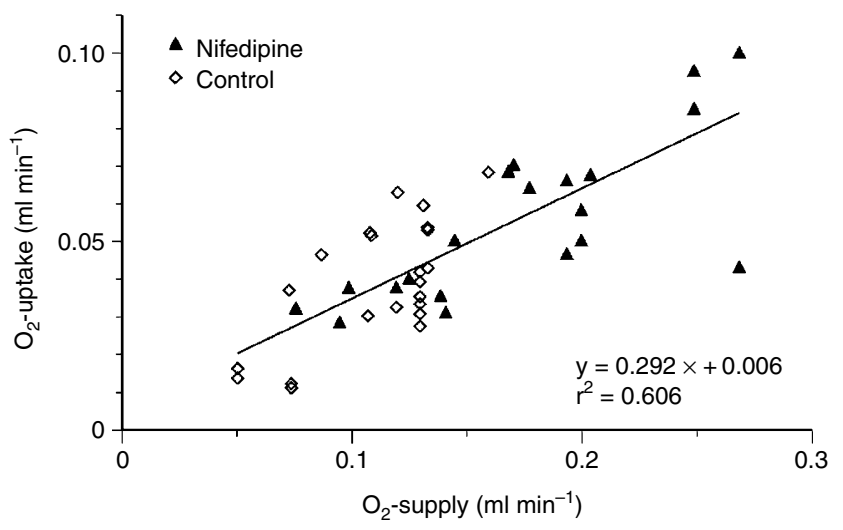

Figure 5 Correlation between $\mathrm{O}_{2}$ supply and $\mathrm{O}_{2}$ uptake during isolated limb perfusion. restricted resulting in a higher glycolytic rate as indicated by a lower glucose concentration in ILP tumours without nifedipine application $\left(0.59 \pm 0.09\right.$ compared to $1.11 \pm 0.22 \mu \mathrm{mol} \mathrm{g}^{-1}$ in the contralateral control tumours which were not isolated-perfused), and higher lactate levels in the isolated perfused limb tumours $\left(27.0 \pm 3.5 v s 9.3 \pm 1.7 \mu \mathrm{mol} \mathrm{g}^{-1}\right.$ in the contralateral leg). However, the higher glycolytic rate during ILP did not have a strong impact on the bioenergetic status. In isolated perfused tumours (without nifedipine) the ATP levels were $0.66 \pm 0.08$ compared to $1.18 \pm 0.13 \mu \mathrm{mol} \mathrm{g}^{-1}$ in the contralateral non-isolated-perfused tumours. Although the oxygen supply was restricted during ILP per se (due to the reduced haematocrit of the perfusate which results in a lower oxygen transport capacity), a stable bioenergetic status was maintained.

With nifedipine infusion during ILP, tumour perfusion substantially increased and resulted in a considerably higher nutrient supply which was reflected by a higher (though not statistically significant) tumour glucose concentration $\left(1.39 \pm 0.39 \mu \mathrm{mol} \mathrm{g}^{-1}\right.$ during nifedipine application $v s \quad 0.59 \pm 0.09 \mu \mathrm{mol} \mathrm{g}^{-1}$ in ILP tumours without nifedipine). However, since the oxygenation status was not improved by nifedipine neither the lactate levels $\left(25.7 \pm 2.2\right.$ vs $\left.27.0 \pm 3.5 \mu \mathrm{mol} \mathrm{g}^{-1}\right)$ nor the ATP concentration $\left(0.79 \pm 0.11\right.$ vs $\left.0.66 \pm 0.08 \mu \mathrm{mol} \mathrm{g}^{-1}\right)$ markedly changed during nifedipine treatment compared to tumours during ILP without nifedipine. Obviously, the increase in tumour blood flow had practically no impact on the metabolic or bioenergetic status of the tumour.

\section{DISCUSSION}

Pressure-controlled ILP allows the administration of anti-cancer agents to a tumour at high doses with reduced systemic toxicity. However, due to the compromised microcirculation found in many experimental and human tumours a sub-optimum delivery (pharmacokinetics) of chemotherapeutic agents can be expected. In addition, the deterioration and heterogeneity of tumour blood flow is responsible for hypoxia in tumours which in turn reduces the efficacy of oxygen-dependent chemotherapeutic agents. For this reason, a supportive treatment modality (e.g., nifedipine application) which leads to a reduction of heterogeneity or an improvement of tumour blood flow and/or a reduction of hypoxia might be of clinical interest.

\section{Tumour perfusion}

The effect of CCBs on tumour perfusion has been investigated extensively over the last two decades. Wood and Hirst (1989) described dose-dependent effects of different types of CCBs on tumour perfusion and radiosensitivity. While verapamil, nifedipine and diltiazem enhanced radiosensitivity at low doses and increased radioresistance at higher doses, flunarizine, which exhibits only limited suppression of cardiac contractility (Robertson and Robertson, 1996), increased radiosensitivity at all dose levels. Pressure-

Table I Arterio-venous $\mathrm{O}_{2}$ difference $\left(\operatorname{avDO} \mathrm{O}_{2}\right), \mathrm{O}_{2}$ uptake and $\mathrm{O}_{2}$ utilisation $\left(\mathrm{O}_{2}\right.$ extraction rate) in the isolated perfused tumour-bearing limb immediately prior to ( $\mathrm{t}=0 \mathrm{~min}$ ) and during ( $\mathrm{t}=15$ and $30 \mathrm{~min}$ ) infusion of nifedipine or vehicle

\begin{tabular}{|c|c|c|c|c|c|c|}
\hline \multirow[b]{2}{*}{$t(\min )$} & \multicolumn{2}{|c|}{$\begin{array}{c}\operatorname{avDO}_{2}\left(\mathrm{ml} \mathrm{O}_{2} \mathrm{ml}^{-1}\right. \\
\text { perfusate })\end{array}$} & \multicolumn{2}{|c|}{$\mathrm{O}_{2}$ uptake $\left(\mathrm{ml} \min ^{-1}\right)$} & \multicolumn{2}{|c|}{$\mathrm{O}_{2}$ utilisation $(\%)$} \\
\hline & Control & Nifedipine & Control & Nifedipine & Control & Nifedipine \\
\hline 0 & $0.038 \pm 0.003$ & $0.04 I \pm 0.002$ & $0.051 \pm 0.006$ & $0.049 \pm 0.007$ & $39 \pm 3$ & $43 \pm 2$ \\
\hline 15 & $0.034 \pm 0.003$ & $0.032 \pm 0.003$ & $0.04 I \pm 0.006$ & $0.062 \pm 0.008 *$ & $36 \pm 4$ & $33 \pm 2$ \\
\hline 30 & $0.033 \pm 0.003$ & $0.031 \pm 0.003$ & $0.036 \pm 0.004$ & $0.050 \pm 0.006$ & $34 \pm 3$ & $32 \pm 2$ \\
\hline
\end{tabular}

Data represent mean \pm s.e.m. from at least 10 perfusion experiments; ${ }^{*} P<0.05$ nifedipine vs control. 
controlled isolated perfusion permits the use of all classes of CCBs irrespective of their suppression of cardiac contractility since PP can be maintained by adjusting the perfusate flow rate. Vessels feeding the tumour dilate upon application of CCBs, while microvessels within hypoxic tumours might not be able to react adequately to vasodilatory stimuli since in their acidic and hypoxic microenvironment they are already maximally dilated (Vaupel et al, 1989) or are lacking a functional smooth muscle layer. Thus an increased flow rate will result in an enhanced perfusion in both normal and tumour tissue as long as the vascular beds of these tissues lie in series with one another. If both vessels are located parallel to each other, dilation of the host tissue vessels (and not of the tumour vasculature) may induce a redirection of blood flow in favour of the surrounding normal tissue ('steal' phenomenon). However, the results of the present study show that the nifedipine-induced increase in perfusion rate actually leads to an increased tumour blood flow. Perfusate flow rate and tumour RBC flux (as measured by the laser Doppler technique) increased almost in parallel, except towards the end of the infusion period when the perfusate flow was reduced by approximately $30 \%$ (Figure 2), whereas the RBC flux showed a sustained increased value (Figure $3 \mathrm{~A}$ ) indicating a vasodilatatory effect of nifedipine during this period (Figure $3 \mathrm{~B}$ ). Tumour perfusion increased during nifedipine application by $50-70 \%$ of the pre-treatment value. These data clearly indicate that nifedipine-induced vasodilation does not induce a 'steal' effect of the surrounding normal tissue of the isolated perfused leg (e.g., skeletal muscle). The improvement of tumour blood flow seen in the present experiments was comparable to that found in other studies where increases ranged from approximately $+30 \%$ to a maximum of $+200 \%$ using various kinds of CCBs (Kaelin et al, 1984; Vaupel and Menke, 1987; Wood and Hirst, 1989; Dewhirst et al, 1992; Zenke et al, 1996; Muruganandham et al, 1999). Wu et al (1997) demonstrated that an enhanced flow rate is accompanied by improved pharmacokinetics of the anti-cancer drug melphalan. Raising the perfusate flow rate from 4 to $8 \mathrm{ml} \mathrm{min}^{-1}$ led to a two-fold increase in melphalan concentration in the tumour tissue. Zenke et al (1996) showed that co-administration of diltiazem and the anti-cancer drug nimustine resulted in a $39 \%$ increase in intra-tumoural blood flow and a higher concentration of nimustine in rat gliomas. The improved microcirculation seen upon application of nifedipine as shown in our study may therefore present a useful and appropriate means of promoting the delivery of anti-cancer agents to the tumour tissue.

\section{Tumour oxygenation and oxygen utilisation}

In the present study, $\mathrm{pO}_{2}$ values measured in tumours of isolated perfused limbs were lower (median $\mathrm{pO}_{2}: 2 \mathrm{mmHg}$, fraction of hypoxic $\mathrm{pO}_{2}$ values $\leqslant 2.5 \mathrm{mmHg}$ : $62 \%$ ) than in non-perfused contralateral control tumours with comparable volumes (median $\mathrm{pO}_{2}$ : 4-13 mmHg, fraction of hypoxic $\mathrm{pO}_{2}$ values: $10-40 \%$ ) (Kelleher and Vaupel, 1993; Kelleher et al, 1995, 1998a). These data indicate that during isolated limb perfusion $\mathrm{O}_{2}$-supply conditions were restricted (compared to control conditions in non-perfused limbs). This is partially due to the lower $\mathrm{cHb}$ of the perfusate $\left(74 \pm 2 \mathrm{~g} \mathrm{l}^{-1}\right)$ compared to whole blood. Control measurements in the normal subcutis of perfused hind limbs (non-tumour bearing) and non-artificially perfused legs also showed poorer oxygenation during ILP (median $\mathrm{pO}_{2}=37 \mathrm{mmHg}$ in subcutis during ILP and $49 \mathrm{mmHg}$ in control legs). In many experimental ILP studies (Bonen et al, 1994) as well as in the clinical setting, perfusates with reduced $\mathrm{cHb}$ (compared to normal whole blood) or even erythrocyte-free perfusates were used. Enhanced flow rates (e.g., during nifedipine application) might therefore (at least partially) compensate for the reduced oxygen transport capacity associated with a low $\mathrm{cHb}$.
Many studies have demonstrated an increased tumour blood flow upon application of CCBs but the postulated effect on tumour oxygenation has generally not been documented. Based on mathematical simulation experiments, Secomb et al (1995) proposed that a fraction of hypoxic $\mathrm{pO}_{2}$-values of $30 \%$ would only be abolished if the flow rate were to be increased by a factor of 4 or more. An improvement in tumour oxygenation was reported in two studies by Dewhirst et al (1992) and Muruganandham et al (1999) where tumour blood flow increased to two- and three-fold the baseline values, respectively. Using a dorsal skin flap preparation Dewhirst et al (1992) demonstrated that flunarizine enhanced perivascular $\mathrm{pO}_{2}$ by approximately $50 \%$ in the tumour center $\left(\mathrm{pO}_{2}\right.$ prior to drug administration $25 \mathrm{mmHg}$, with an increase of $12 \mathrm{mmHg}$ ). Muruganandham et al (1999) reported a diltiazem-induced improvement in tumour oxygenation of $25 \%$ in a subcutaneously growing tumour. The present study failed to show a marked effect of nifedipine on tumour oxygenation during ILP. Although tumour perfusion increased by $50 \%$ during nifedipine application (Figure $3 \mathrm{~A}$ ), the mean tumour $\mathrm{pO}_{2}$ rose only slightly by $2-$ $3 \mathrm{mmHg}$ (Figure 4). These results are still in accordance with previous studies demonstrating that CCBs can affect the oxygen consumption rate of tumour cells (Biaglow et al, 1986; Vaupel and Mueller-Klieser, 1986). These studies showed that with high concentrations of verapamil and other CCBs the $\mathrm{O}_{2}$ utilisation in several tumour cell lines can be reduced under in vitro conditions by up to $30 \%$. However, in vivo, the tissue concentrations of these drugs are presumably much lower inducing a less pronounced reduction. In addition, previous studies also clearly demonstrated that a reduction of $\mathrm{O}_{2}$ consumption rate by only $30 \%$ is not sufficient to cause a significant improvement in the oxygenation status of a tumour (Thews et al, 1999). For this reason, the results of the present study do not necessarily contradict previously published in vitro data.

Since the oxygenation status of a tissue results from a dynamic steady-state between the oxygen supply and the cellular $\mathrm{O}_{2}$ consumption, one possible explanation for the lack of oxygenation improvement during nifedipine application may be an increase in $\mathrm{O}_{2}$ uptake during the treatment. Calculating the oxygen uptake from the $\mathrm{avDO}_{2}$ and the perfusion rate, it became obvious that with a greater oxygen supply (as a result of a higher perfusion rate during nifedipine application) the $\mathrm{O}_{2}$-uptake by the tumour increased linearly (Figure 5). Previous studies by Gullino et al (1967a,b) and Kallinowski et al (1989a,b) showed that the tumour $\mathrm{O}_{2}$ consumption is dependent on the oxygen availability as long as a 'saturation level' of the $\mathrm{O}_{2}$ supply is not reached. An improvement in the convective $\mathrm{O}_{2}$ transport (by increased perfusion) will only reduce tumour hypoxia if the $\mathrm{O}_{2}$ supply greatly exceeds the consumption rate. Due to the reduced haemoglobin level during ILP, the oxygen transport capacity of the perfusate is diminished $\left(0.11 \mathrm{ml} \mathrm{O}_{2}\right.$ per $\mathrm{ml}$ blood during ILP $v s 0.2 \mathrm{ml} \mathrm{O}_{2}$ per $\mathrm{ml}$ blood in controls) resulting in a restricted supply situation. Obviously, the $\mathrm{O}_{2}$ supply in the present study was markedly lower than the 'saturation level' and the convective $\mathrm{O}_{2}$ transport during ILP did not meet the demands of the tumour tissue. During ILP therefore, where the $\mathrm{O}_{2}$ transport capacity is reduced, an improvement in the perfusion rate of $50-100 \%$ is probably not sufficient to bring about a significant increase in the median tumour $\mathrm{pO}_{2}$.

As a result of the restricted oxygen supply during ILP (due to the reduced haematocrit of the perfusate), the lactate levels in tumours of isolated perfused limbs were significantly higher than in tumours of contralateral control limbs, indicating a much higher glycolytic rate. However, the higher glycolytic rate had only a minor impact on the bioenergetic status resulting in ATP levels which are comparable to those found previously in untreated tumours (Vaupel et al, 1994). Although nifedipine application during ILP increased tumour perfusion by approximately $60 \%$ (Figure 3 ) and in turn the nutrient and oxygen supply, only the 
glucose concentration in the tumour was elevated. Nifedipine had almost no impact on the bioenergetic status, a finding which is in good accordance to an earlier study demonstrating the energy status to be relatively stable despite substantial changes in blood flow and tissue oxygenation providing tumour perfusion does not fall below a certain threshold (Vaupel et al, 1994).

In conclusion, nifedipine can significantly improve tumour perfusion during pressure-controlled ILP. 'Steal phenomena' in favour of the surrounding normal tissue and oedema formation were not observed. Nifedipine can enhance tumour microcirculation and may therefore promote the delivery (pharmacokinetics) of anti-cancer agents. Although the application of this calcium

\section{REFERENCES}

Biaglow JE, Varnes ME, Jacobson B, Suit HD (1986) Effect of calcium channel blocking drugs on tumor cell oxygen utilization. Adv Exp Med Biol 200: $583-589$

Bonen A, Clark MG, Henriksen EJ (1994) Experimental approaches in muscle metabolism: hindlimb perfusion and isolated muscle incubations. Am J Physiol 266: E1-E16

Cornwell MM, Pastan I, Gottesman MM (1987) Certain calcium channel blockers bind specifically to multidrug-resistant human $\mathrm{KB}$ carcinoma membrane vesicles and inhibit drug binding to P-glycoprotein. J Biol Chem 262: $2166-2170$

Creech O, Krementz ET, Ryan RF, Winblad JN (1958) Chemotherapy of cancers: regional perfusion utilizing an extracorporeal circuit. Ann Surg 148: $616-631$

de Wilt JH, Manusama ER, van Tiel ST, van Ijken MG, ten Hagen TL, Eggermont AM (1999) Prerequisites for effective isolated limb perfusion using tumour necrosis factor alpha and melphalan in rats. $\mathrm{Br} J$ Cancer 80: $161-166$

Dewhirst MW, Ong ET, Madwed D, Klitzman B, Secomb T, Brizel D, Bonaventura J, Rosner G, Kavanagh B, Edwards J (1992) Effects of the calcium channel blocker flunarizine on the hemodynamics and oxygenation of tumor microvasculature. Radiat Res 132: $61-68$

Eggermont AM, Schraffordt-Koops H, Lienard D, Kroon BB, van Geel AN, Hoekstra HJ, Lejeune FJ (1996) Isolated limb perfusion with high-dose tumor necrosis factor-alpha in combination with interferon-gamma and melphalan for nonresectable extremity soft tissue sarcomas: a multicenter trial. J Clin Oncol 14: 2653-2665

Fontijne WP, Mook PH, Elstrodt JM, Schraffordt-Koops H, Oldhoff J, Wildevuur CR (1985a) Isolated hindlimb perfusion in dogs: the effect of perfusion pressures on the oxygen supply ( $\mathrm{ptO}_{2}$ histogram) to the skeletal muscle. Surgery 97: 278-284

Fontijne WP, Mook PH, Koops HS, Oldhoff J, Wildevuur CR (1985b) Improved tissue perfusion during pressure regulated hyperthermic regional isolated perfusion. A clinical study. Cancer 55: 1455-1461

Gullino PM, Grantham FH, Courtney AH (1967a) Utilization of oxygen by transplanted tumors in vivo. Cancer Res 27: 1020-1030

Gullino PM, Grantham FH, Courtney AH, Losonczy I (1967b) Relationship between oxygen and glucose consumption by transplanted tumors in vivo. Cancer Res 27: 1041 - 1052

Helson L (1984) Calcium channel blocker enhancement of anticancer drug cytotoxicity - a review. Cancer Drug Deliv 1: 353-361

Hill RP, Stirling D (1987) Oxygen delivery and tumour response. In Radiation Research, Proceedings of the 8th International Congress of Radiation Research, Fielden EM, Fowler JF, Hendry JH, Scott D (eds) pp 725-730 London: Taylor \& Francis

Hohenberger P, Kettelhack C (1998) Clinical management and current research in isolated limb perfusion for sarcoma and melanoma. Oncology 55: $89-102$

Honn KV, Onoda JM, Pampalona K, Battaglia M, Neagos G, Taylor JD, Diglio CA, Sloane BF (1985) Inhibition by dihydropyridine class calcium channel blockers of tumor cell-platelet-endothelial cell interactions in vitro and metastasis in vivo. Biochem Pharmacol 34: 235-241

Höckel M, Vaupel P (2001) Tumor hypoxia: definitions and current clinical, biologic, and molecular aspects. J Natl Cancer Inst 93: 266-276

Jirtle RL (1988) Chemical modification of tumour blood flow. Int J Hyperthermia 4: $355-371$ channel blocker increases oxygen availability to the tumour the improvement of perfusion by nifedipine does not result in a substantial reduction of tumour hypoxia. On the basis of these results, nifedipine application during ILP can be expected to increase the delivery of anti-cancer drugs to the tumour and by this improve the efficacy of pressure-controlled ILP.

\section{ACKNOWLEDGEMENTS}

This study was supported by a grant from the Dr. med. Wulf Vater Foundation, Germany.
Kaelin WG, Shrivastav S, Jirtle RL (1984) Blood flow to primary tumors and lymph node metastases in SMT-2A tumor-bearing rats following intravenous flunarizine. Cancer Res 44: 896-899

Kallinowski F, Schlenger KH, Kloes M, Stohrer M, Vaupel P (1989a) Tumor blood flow: the principal modulator of oxidative and glycolytic metabolism, and of the metabolic micromilieu of human tumor xenografts in vivo. Int J Cancer 44: $266-272$

Kallinowski F, Schlenger KH, Runkel S, Kloes M, Stohrer M, Okunieff P, Vaupel P (1989b) Blood flow, metabolism, cellular microenvironment, and growth rate of human tumor xenografts. Cancer Res 49: 3759-3764

Kelleher DK, Engel T, Vaupel PW (1995) Changes in microregional perfusion, oxygenation, ATP and lactate distribution in subcutaneous rat tumours upon water-filtered IR-A hyperthermia. Int J Hyperthermia 11: $241-255$

Kelleher DK, Nauth C, Thews O, Krueger W, Vaupel P (1998a) Localized hypothermia: Impact on oxygenation, microregional perfusion, metabolic and bioenergetic status of subcutaneous rat tumours. Br J Cancer 78: $56-$ 61

Kelleher DK, Thews O, Vaupel P (1998b) Regional perfusion and oxygenation of tumors upon methylxanthine derivative administration. Int $J$ Radiat Oncol Biol Phys 42: 861-864

Kelleher DK, Vaupel P (1993) Nicotinamide exerts different acute effects on microcirculatory function and tissue oxygenation in rat tumors. Int $J$ Radiat Oncol Biol Phys 26: $95-102$

Krüger W, Mayer WK, Schaefer C, Stohrer M, Vaupel P (1991) Acute changes of systemic parameters in tumour-bearing rats, and of tumour glucose, lactate, and ATP levels upon hyperthermia and/or hyperglycaemia. J Cancer Res Clin Oncol 117: 409-415

Muruganandham M, Kasiviswanathan A, Jagannathan NR, Raghunathan P Jain PC, Jain V (1999) Diltiazem enhances tumor blood flow: MRI study in a murine tumor. Int J Radiat Oncol Biol Phys 43: 413-421

Nagel K, Ghussen F, Krüger I, Isselhard W (1987) Miniature equipment for the perfusion of rat limbs. Res Exp Med 187: 1-8

Omlor GH, Vaupel P, Alexander C (eds) (1995) Isolated hyperthermic limb perfusion. Berlin: Springer

Onoda JM, Nelson KK, Taylor JD, Honn KV (1989) In vivo characterization of combination antitumor chemotherapy with calcium channel blockers and cis-diamminedichloroplatinum(II). Cancer Res 49: 2844-2850

Pisters PW, Feig BW, Leung DH, Brennan MF (1997) New developments in soft tissue sarcoma. Cancer Treat Res 90: 91-107

Robertson RM, Robertson D (1996) Drugs used for the treatment of myocardial ischemia. In Goodman \& Gilman's The pharmacological basis of therapeutics, Hardman JG, Goodman Gilman A, Limbird LE (eds) pp 759-779 New York: McGraw-Hill

Schraffordt-Koops H., Eggermont AM, Lienard D, Kroon BB, Hoekstra HJ, van Geel AN, Nieweg OE, Lejeune FJ (1998) Hyperthermic isolated limb perfusion with tumour necrosis factor and melphalan as treatment of locally advanced or recurrent soft tissue sarcomas of the extremities. Radiother Oncol 48: 1-4

Secomb TW, Hsu R, Ong ET, Gross JF, Dewhirst MW (1995) Analysis of the effects of oxygen supply and demand on hypoxic fraction in tumors. Acta Oncol 34: $313-316$ 
Seynhaeve ALB, de Wilt JHW, van Tiel ST, Eggermont AMM, ten Hagen TLM (2002) Isolated limb perfusion with actinomycin D and TNF-alpha results in improved tumour response in soft-tissue sarcoma-bearing rats but is accompanied by severe local toxicity. Br J Cancer 86: $1174-1179$

Smits GJ, Roman RJ, Lombard JH (1986) Evaluation of laser-Doppler flowmetry as a measure of tissue blood flow. J Appl Physiol 61: 666-672

Thews O, Kelleher DK, Hummel M, Vaupel P (1999) Can tumor oxygenation be improved by reducing cellular oxygen consumption? Adv Exp Med Biol 471: $525-532$

Vaupel P, Kallinowski F, Okunieff P (1989) Blood flow, oxygen and nutrient supply, and metabolic microenvironment of human tumors: a review. Cancer Res 49: 6449-6465

Vaupel P, Kelleher DK, Engel T (1994) Stable bioenergetic status despite substantial changes in blood flow and tissue oxygenation in a rat tumour. Br J Cancer 69: $46-49$

Vaupel P, Menke H (1987) Blood flow, vascular resistance and oxygen availability in malignant tumours upon intravenous flunarizine. Adv Exp Med Biol 215: 393-398

Vaupel P, Menke H (1989) Effect of various calcium antagonists on blood flow and red blood cell flux in malignant tumors. Progr Appl Microcirc 14: $88-103$

Vaupel P, Mueller-Klieser W (1986) Verapamil inhibits the respiration rate of cancer cells. Adv Exp Med Biol 200: 645-648
Vaupel P, Thews O, Hoeckel M (2001) Treatment resistance of solid tumors - Role of hypoxia and anemia. Med Oncol 18: 243-259

Wood PJ, Hirst DG (1988) Cinnarizine and flunarizine as radiation sensitisers in two murine tumours. Br J Cancer 58: $742-745$

Wood PJ, Hirst DG (1989) Modification of tumour response by calcium antagonists in the SCVII/St tumour implanted at two different sites. Int $J$ Radiat Biol 56: 355-367

Workman P, Twentyman P, Balkwill F, Balmain A, Chaplin DJ, Double JA, Embleton J, Newell D, Raymond R, Stables J, Stephens T, Wallace J (1998) United Kingdom Co-ordinating Committee on Cancer Research (UKCCCR) Guidelines for the Welfare of Animals in Experimental Neoplasia (Second Edition). Br J Cancer 77: 1-10

Wu ZY, Smithers BM, Parsons PG, Roberts MS (1997) The effects of perfusion conditions on melphalan distribution in the isolated perfused rat hindlimb bearing a human melanoma xenograft. $B r J$ Cancer 75: $1160-$ 1166

Zenke K, Nakagawa K, Kumon Y, Ohta S, Hatakeyama T, Sakaki S (1996) A strategy for selective anti-cancer drug concentration increase in rat glioma tissue with $\mathrm{Ca}^{2+}$-channel blocker co-administration: calcium kinetics in intra-glioma arteriolar smooth muscle cells. J Neurooncol 30: 25-36 